\title{
Experimental study on the applicability of Westergaard's formula for calculating earthquake-induced hydrodynamic pressure in small lake
}

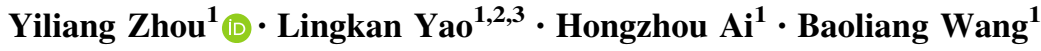

Received: 26 May 2017/Revised: 14 September 2017/Accepted: 30 October 2017/Published online: 17 November 2017

(c) The Author(s) 2017. This article is an open access publication

\begin{abstract}
Moraine-dammed lake outbursts usually threaten highways, railways, and key facilities in alpine regions. The varying amplitudes and distribution of hydrodynamic pressures significantly affect the stability of the dam. We utilize a shaking table to investigate the development of hydrodynamic pressure caused by different sinusoidal waves and seismic Wolong wave. A series of shaking table tests indicate that the hydrodynamic pressure variation significantly follows seismic acceleration wave motion. The maximum hydrodynamic pressures calculated by Westergaard's equation are compared with the experimental values under different waves. It is shown that the Westergaard's values are lower than the experimental ones under the sinusoidal waves. However, the Westergaard's method is able to predict the earthquake-induced hydrodynamic pressure caused by Wolong wave in small lake with desirable accuracy.
\end{abstract}

Yiliang Zhou

940387856@qq.com

Lingkan Yao

yaolk@swjtu.edu.cn

Hongzhou Ai

a479517572@163.com

Baoliang Wang

blwang0516@163.com

1 School of Civil Engineering, Southwest Jiaotong University, Chengdu 610031, Sichuan, China

2 MOE Key Laboratory of High-speed Railway Engineering, Southwest Jiaotong University, Chengdu 610031, Sichuan, China

3 National Engineering Laboratory for Technology of Geological Disaster Prevention in Land Transportation, Chengdu 610031, China
Keywords Moraine dam · Hydrodynamic pressure . Shaking table $\cdot$ Westergaard $\cdot$ Small lake

\section{Introduction}

Sichuan-Tibet railway has been included in China western development strategy. Sichuan-Tibet railway is expected to across the Hengduan mountains from the east of Tibet plateau, and this area has the geomorphic features of high altitude and large elevation difference and distributes a large amount of glacial lakes. In the Parlung Zangbo river basin, for example, there are 461 glaciers and 131 glacial lakes of different sizes [1, 2]. In nearly 40 years, there had eight large-scale debris flow from glacial lake outburst floods (GLOF), blocking and damaging roads from 20 to 270 days. For example, in July 1988, debris flow resulting from GLOF in Midui destroyed nearly 30-km SichuanTibet roads and blocked the route for half a year [3]. The lake outbursts pose a catastrophe risk to the Sichuan-Tibet railway coming across the Parlung Zangbo river basin, which is a challenge in China's railway history [4]. Moreover, Parlung Zangbo river basin is located in strong earthquake regions where more than 40,000 earthquakes have been recorded since 1970, and more than 3000 of these earthquakes were greater than Ms3.0, posing a potential threat to the stability of moraine dams [5]. In recent years, with the global warming and glacial retreating, moraine-dammed lake disaster has a tendency to increase. Therefore, the moraine-dammed lake outbursts caused by earthquakes have become a special environmental geological hazard to railway route [6].

The seismic action not only directly threatens the stability of the dams, but also causes the water movement of 
upstream reservoir. Two forces acting on a dam during an earthquake are the seismic inertial force of the dam itself and water pressure. A large quantity of water is forced to act on the dam repeatedly, and thus, the water pressure on the dam is not negligible [7-9]. Westergaard first proposed an expression for the hydrodynamic pressure exerted on the vertical upstream face of concrete dam, assuming that the boundary was semi-infinite and the excitation wave was horizontal harmonic wave [10]. The following approximate formula was obtained [10]:

$P=\frac{7}{8} \rho k_{h} g \sqrt{h(h-y)}$,

where $y$ denotes the water heights, $P$ is the maximum hydrodynamic pressures at height $y, h$ is the reservoir depth, $\rho$ is the unit density of water, $k_{h}$ is the seismic acceleration coefficients in the horizontal direction, and $g$ is the acceleration of gravity $\left(9.8 \mathrm{~m} / \mathrm{s}^{2}\right)$. The approximate formula provides a convenient way for solving the response of the dam-water interactions. In 1953, Zangar developed an experimental solution for the same problem using an electrical analogue and reported extensive results for a variety of non-vertical upstream faces [11]. Based on momentum method and two-dimensional potential flow theory, Chwang solved the hydrodynamic pressure problem with a more general configuration of a dam [12, 13]. Wang et al. [14] modified Westergaard's equation considering the influences of the dam height, elasticity, and reservoir bottom condition. Saleh and Madabhushi [15] investigated the effect of dam-foundation interaction on the hydrodynamic pressure response on the dam face under different earthquake waves using the dynamic centrifuge modeling technique. The results generated by these works were more or less equivalent to the results of Westergaard, and thus, the approximate formula has been widely used to calculate the hydrodynamic pressure loads.

Therefore, it is now widely believed that the earthquakeinduced hydrodynamic pressure is mainly affected by parameters such as the peak ground acceleration (PGA) and the initial water depth. In this paper, the conditions of rigid vertical upstream face and flat bottom were simulated to obtain the hydrodynamic pressure. However, in many cases, the moraine-dammed lake is small, where the boundary reflections may be not negligible. Therefore, it is necessary to study whether Westergaard's formula can be applied to calculate the hydrodynamic pressure in small reservoirs or lakes.

In addition, the moraine dams are formed by an unconsolidated, poorly sorted rock debris or highly heterogeneous mixture of particles [16-18]. The pressure loads acting on this type of dams may lead to failure of the dams and become a critical factor causing the dam to break in the earthquake areas [19]. In this paper, experiments were conducted to study the characteristics of hydrodynamic pressures caused by sinusoidal waves and Wolong wave on a shaking table, and the results were compared with those by Westergaard's formula.

\section{Simulation experiment}

\subsection{Experimental setup}

The simulation experiments were conducted on a shaking table. The experimental setup is illustrated in Fig. 1. The shaking table container was about $3.76 \mathrm{~m}$ in length, $1.75 \mathrm{~m}$

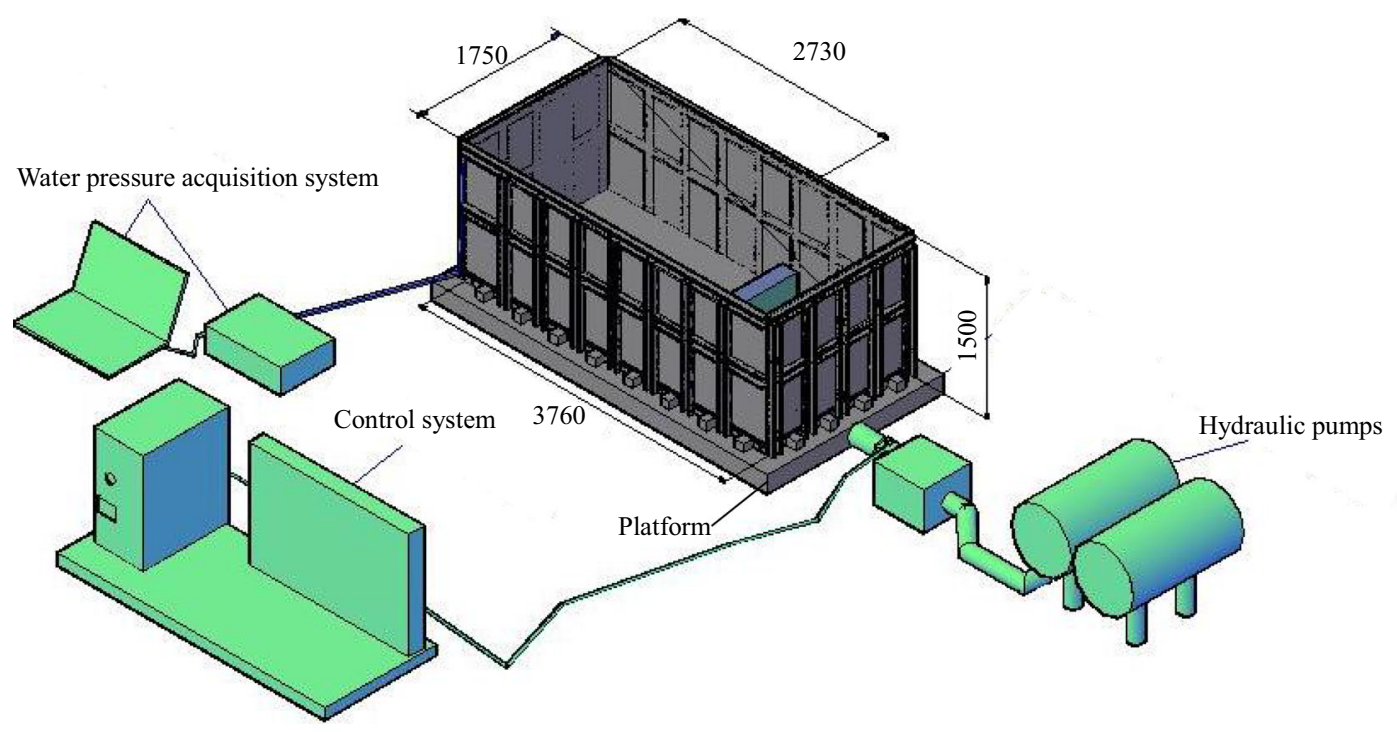

Fig. 1 A typical illustration of the experimental setup (unit:mm) 
in width, and $1.50 \mathrm{~m}$ in height, with a flat bottom, and driven by an electro-hydraulic system. In this experiment, the water container was designed with a dimension of $2.73 \mathrm{~m} \times 1.75 \mathrm{~m} \times 0.35 \mathrm{~m}$ to simulate the morainedammed lake, and the model scale was about $1 / 100$ with the reference of Midui moraine-dammed lake with the area of $300 \mathrm{~m} \times 200 \mathrm{~m}[19,20]$. And the physical phenomena such as the process of water movement are well recorded by camera in the experiments. On the side wall, the hydrodynamic pressure distribution along the wall was measured with six pulsating water pressure sensors located from the bottom to the top at the heights of 2, 8, 14, 20.5, 27.5 , and $31.5 \mathrm{~cm}$. The sensors were numbered as $\mathrm{P}_{1}-\mathrm{P}_{6}$. A detailed illustration of sensor distribution is shown in Fig. 2.

\subsection{Experimental design}

In each test, the input seismic excitation wave was created by the computer control system. When the vibrator receives the signal, the shaking table moves with the triggering wave. In addition, the hydrodynamic pressures are recorded by the water pressure acquisition system. Even after the seismic wave passes by, the acquisition system keeps running until the entire water body becomes stable. The measured hydrodynamic pressures during the earthquakes were calculated by deducting the initial hydrostatic pressure from the total water pressure recorded by the sensors at the corresponding heights. Moreover, each test was repeated twice to reduce the equipment error or human error.

Generally, the predominant period of seismic wave is from 0.15 to $0.5 \mathrm{~s}$, and the frequency ranges from 2 to 6.7 Hz. Therefore, the sinusoidal waves with frequency ranging from 2 to $6 \mathrm{~Hz}$ were used to study the characteristics of hydrodynamic pressures. And the seismic wave adopted the real-time records of the Wenchuan Ms 8.0 earthquake on May 12, 2008, at Wolong, which exhibits the dominant frequency of $2.35 \mathrm{~Hz}$. Meanwhile, white noise was used as a signal source from shaking table to obtain the water fundamental frequency. Details of the seismic waves and PGAs in experiments are shown in Table 1 . The Wolong wave, $3-\mathrm{Hz}$ sinusoidal wave, white noise acceleration waveform, and their spectra by fast Fourier transform (FFT) are shown in Figs. 3, 4, and 5.

\section{Experimental results and discussion}

\subsection{Fluctuation characteristics of hydrodynamic pressure}

Figure 6 shows the change of hydrodynamic pressure recorded by $\mathrm{P}_{1}$ pulsating water pressure sensor. Then, FFT was used to derive the pressure spectrum, and the water fundamental frequency is $0.3325 \mathrm{~Hz}$ (Fig. 7). It is found that the input seismic excitation frequency is far away from the fundamental frequency, indicating that the resonance did not appear.

Figure 8 shows the process of water movement caused by the $3 \mathrm{~Hz}$ sinusoidal wave recorded by video cameras. During the seismic excitation process, water movement was firstly triggered by the side wall motion and then showed a corresponding sinusoidal motion. After the seismic wave passed by, the water waves immediately

Table 1 Seismic wave types and corresponding PGAs

\begin{tabular}{lllllll}
\hline Seismic wave types & \multicolumn{7}{l}{ PGA $\left(\mathrm{m} / \mathrm{s}^{2}\right)$} \\
\hline Wolong wave & $0.05 g$ & $0.1 g$ & $0.15 g$ & $0.2 g$ & $0.25 g$ & $0.3 g$ \\
2-6 Hz sinusoidal wave & $0.1 g$ & $0.2 g$ & $0.3 g$ & - & - & - \\
White noise & $0.1 g$ & - & - & - & - & - \\
\hline
\end{tabular}

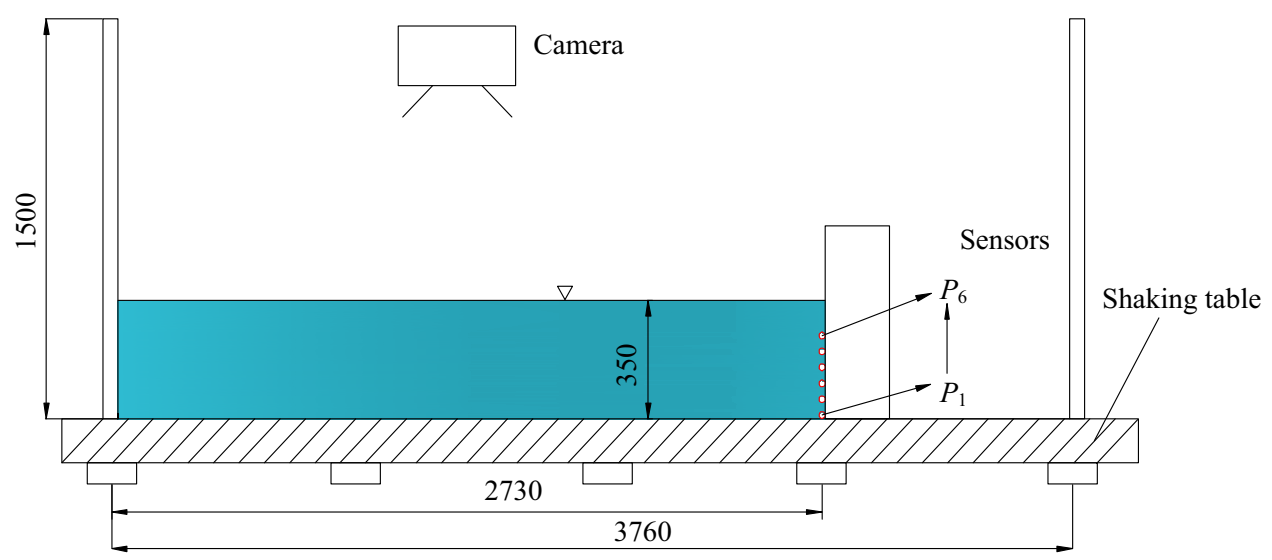

Fig. 2 Schematic diagram of the pulsating water pressure sensor (unit:mm) 


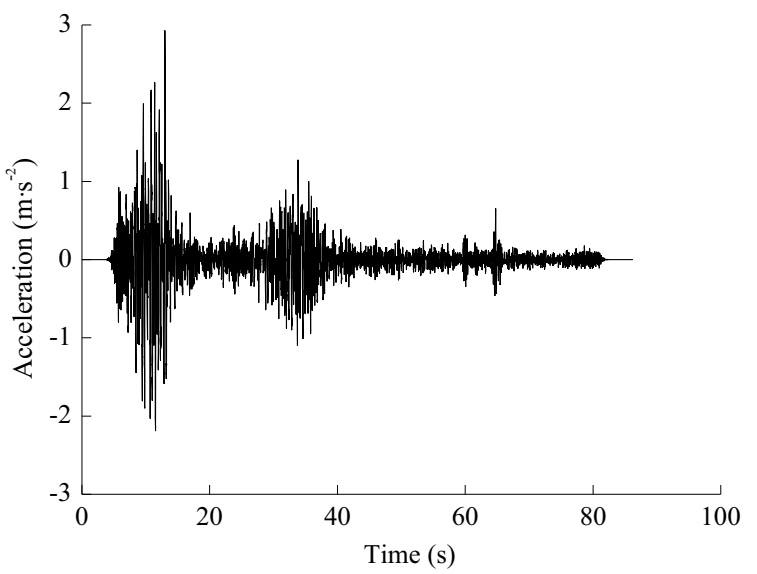

(a)

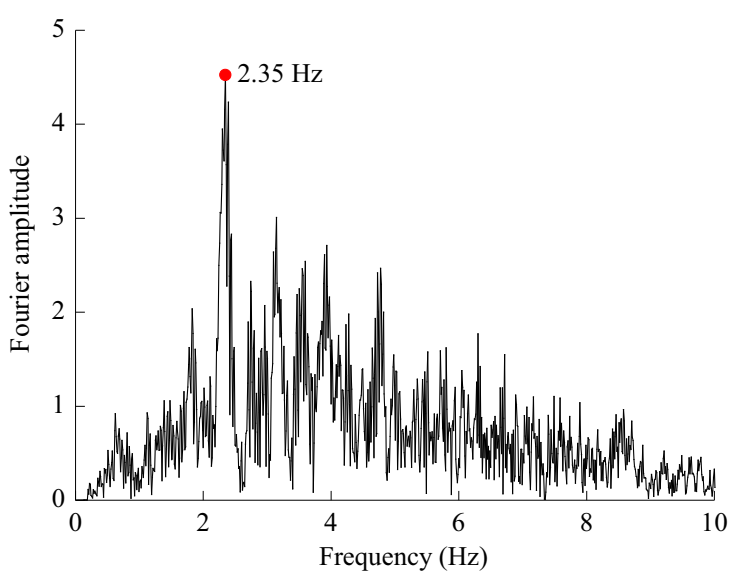

(b)

Fig. 3 Seismic parameters of the Wolong wave. a Acceleration response curve wave in time domain. b Spectrum of the Wolong wave

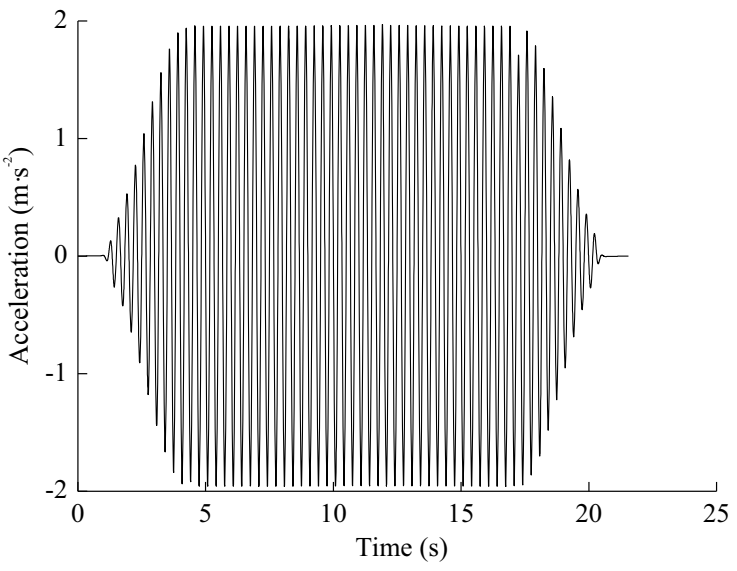

(a)

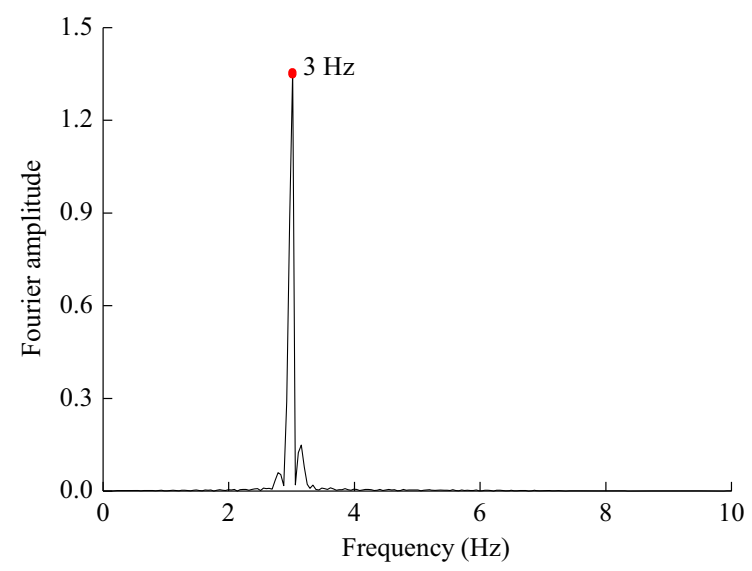

(b)

Fig. 4 Seismic parameters of the $3 \mathrm{~Hz}$ sinusoidal wave. a Acceleration response curve in time domain. b Spectrum of the $3 \mathrm{~Hz}$ sinusoidal wave

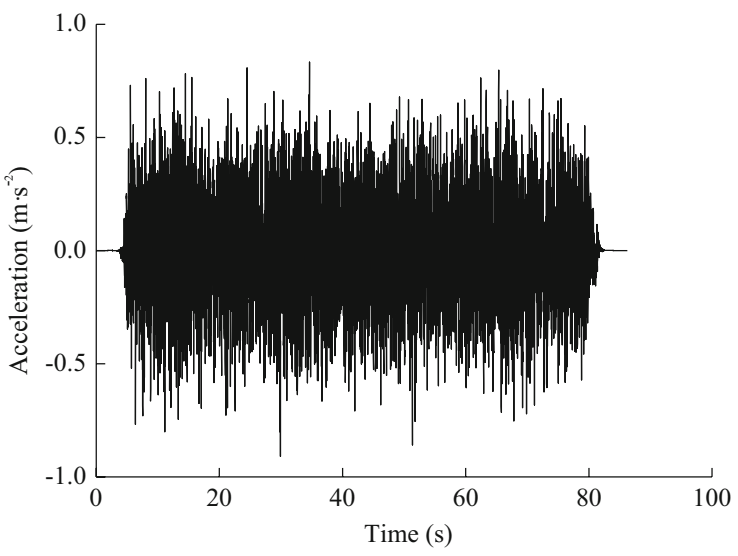

(a)

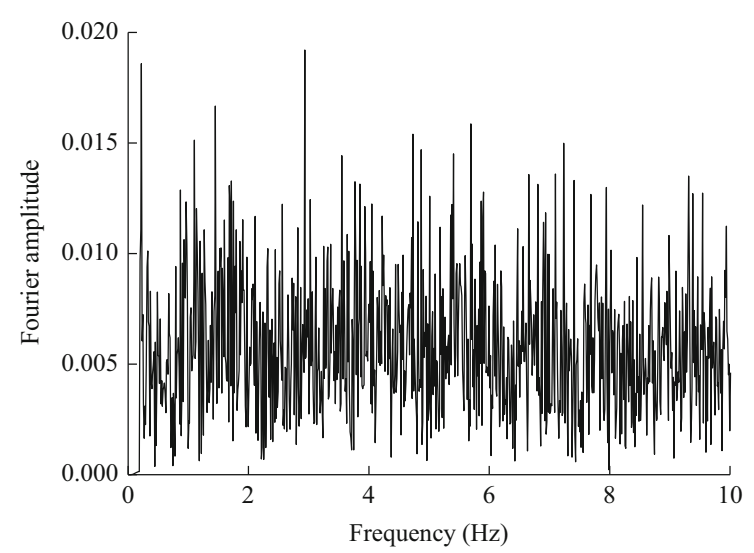

(b)

Fig. 5 Seismic parameters of white noise. a Acceleration response curve in time domain. b Spectrum of white noise 


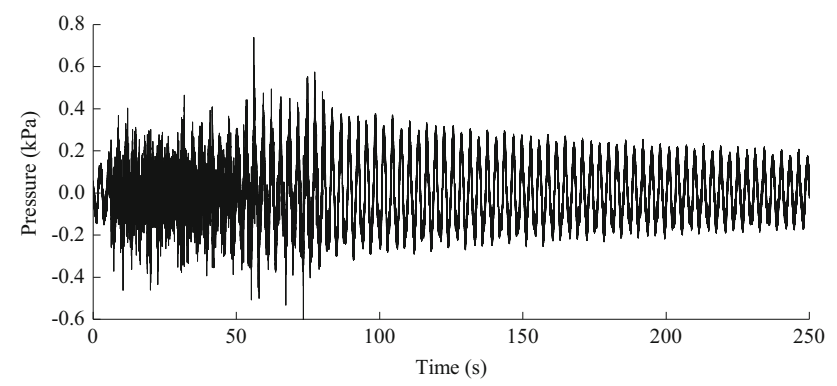

Fig. 6 Fluctuation of hydrodynamic pressure due to white noise $\left(\mathrm{P}_{1}\right.$ $0.1 g$ )

stabilized. Then, the changing characteristics of hydrodynamic pressure were further analyzed according to the measured data of pulsating water pressure sensors.

Figures 9 and 10, respectively, present the hydrodynamic pressures recorded by the $\mathrm{P}_{1}$ sensors attached to the wall under the actions of 3 and $6 \mathrm{~Hz}$ sinusoidal waves, together with the $0.2 \mathrm{~g}$ PGA. The hydrodynamic pressure amplitudes were not increasing with time, but in synchronization with input seismic excitation waves. It is observed that the changing process of hydrodynamic pressures can be divided into two stages: (a) For $0<t<20 \mathrm{~s}$, the hydrodynamic pressures obviously follow seismic acceleration wave motion, and (b) for $20 \mathrm{~s}<t$ after the seismic wave passes by, the hydrodynamic pressure returns simultaneously to zero. The hydrodynamic pressures recorded at other sensors have similar fluctuations. Further, the maximum hydrodynamic pressures under action of different waves were analyzed.

\subsection{Sinusoidal wave action}

The spectrum curves of the measured pressures recorded by $\mathrm{P}_{1}$ sensor under the actions of 3 and $6 \mathrm{~Hz}$ sinusoidal waves are shown in Fig. 11.

As observed in Fig. 11, the predominant frequencies of hydrodynamic pressure are 3 and $6 \mathrm{~Hz}$. They are similar to the spectra of the input sinusoidal waves. This indicates that the response of hydrodynamic pressure is determined

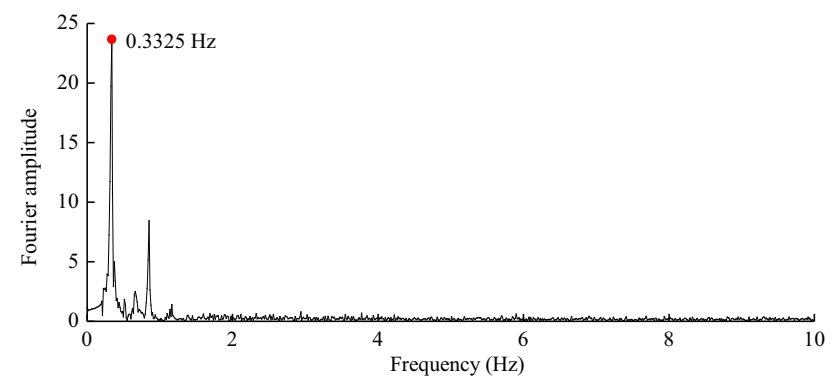

Fig. 7 Spectrum of hydrodynamic pressure due to white noise wave

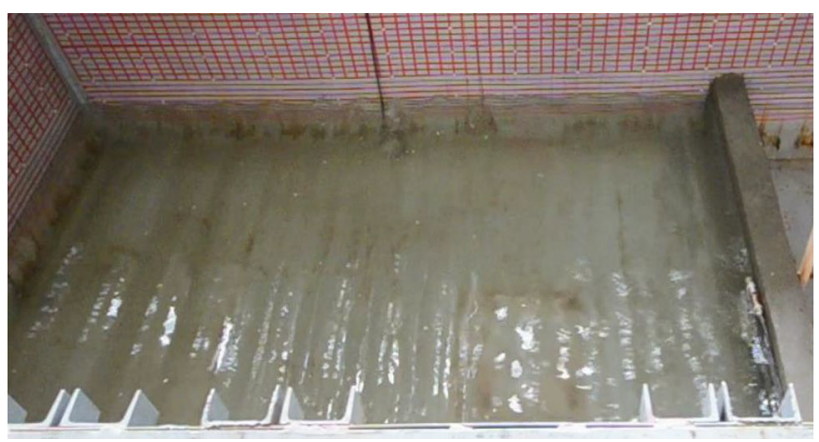

Fig. 8 Water movement due to $3 \mathrm{~Hz}$ sinusoidal wave $(0.2 g)$

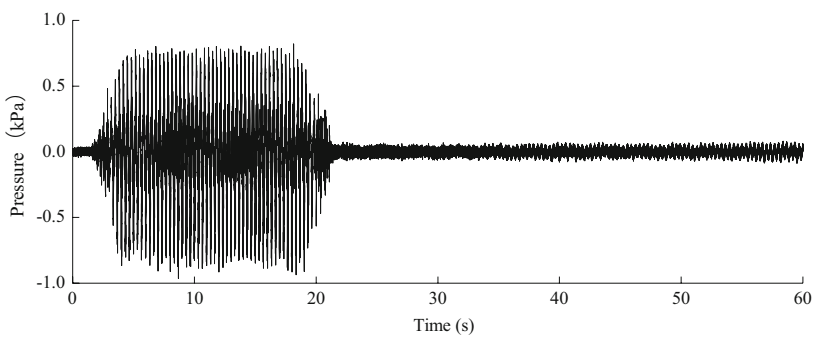

Fig. 9 Fluctuation of hydrodynamic pressure due to $3 \mathrm{~Hz}$ sinusoidal wave $(0.2 g)$

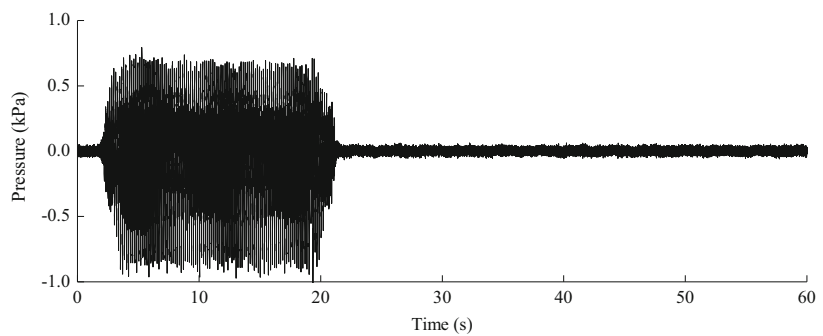

Fig. 10 Fluctuation of hydrodynamic pressure due to 6-Hz sinusoidal wave $(0.2 g)$

by the external seismic excitation wave, and the spectra further reveal the synchronization between the input wave and the hydrodynamic pressure response. In the condition of $35 \mathrm{~cm}$ water depth, the distribution of the maximum hydrodynamic pressure with different frequencies along the water depth under different PGAs of $0.1 g, 0.2 g, 0.3 g$ was analyzed, as shown in Fig. 12.

When PGA is $0.1 g$, the maximum hydrodynamic pressure along the water depth has the same distribution rules. Under the PGAs of $0.2 g$ and $0.3 g$, the distribution of hydrodynamic pressures with different frequencies along the water depth was basically the same, but slightly different due to the equipment error or human error. It is shown that the amplitudes of hydrodynamic pressure are independent of the seismic frequency frequencies when the input seismic excitation frequencies are much larger than water fundamental frequency. 
Comparisons between the experimental hydrodynamic pressures and Westergaard's values indicate that the experimental values are slightly larger than Westergaard's equation. For instance, the experimental hydrodynamic pressures recorded at $\mathrm{P}_{1}$ sensor under the actions of $2-6 \mathrm{~Hz}$ sinusoidal waves were larger than those calculated theoretically by $10 \%-20 \%$. The difference is attributed to the following reason. The real water tank has the boundary
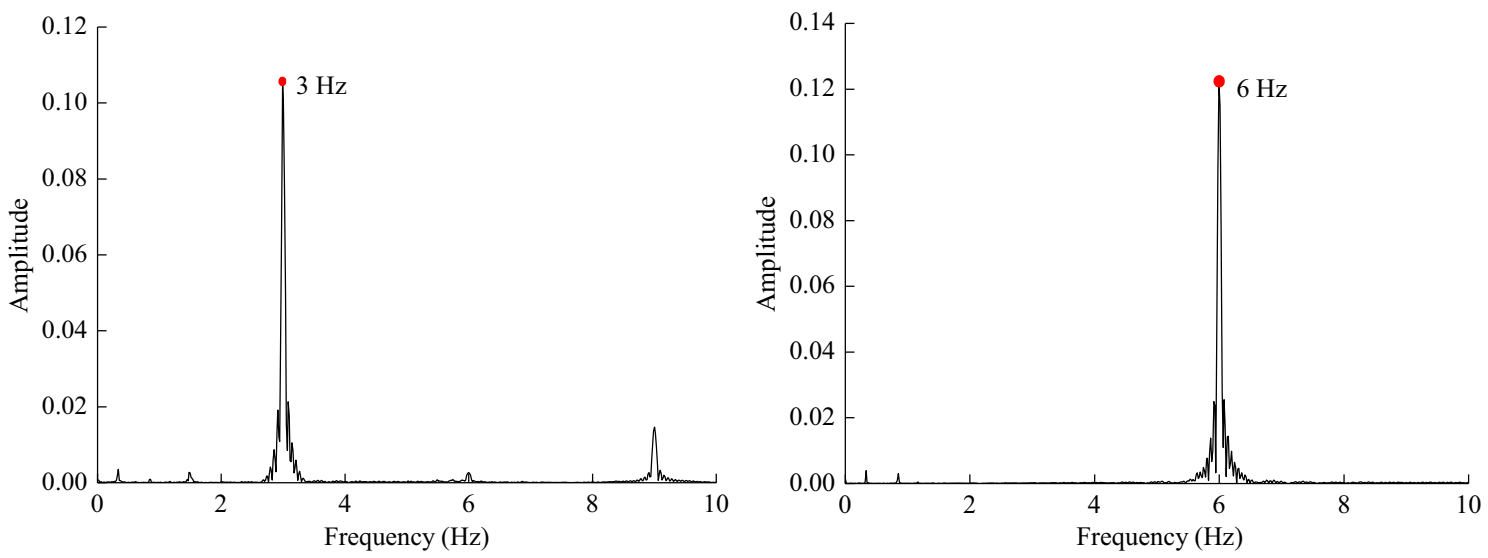

Fig. 11 Fourier amplitude spectrum of hydrodynamic pressure due to 3 and $6 \mathrm{~Hz}$ sinusoidal waves, respectively

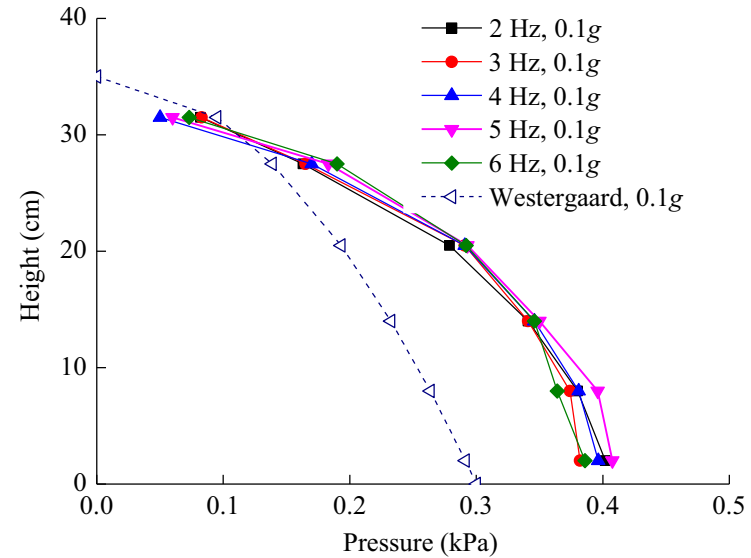

(a)

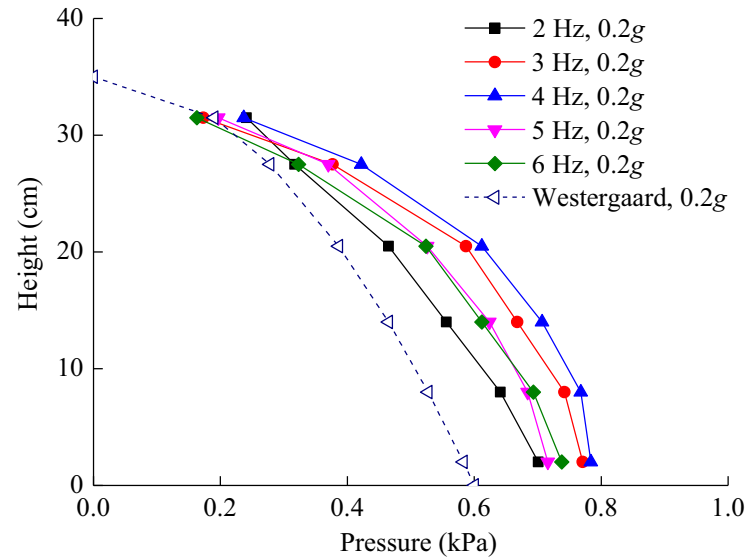

(b)

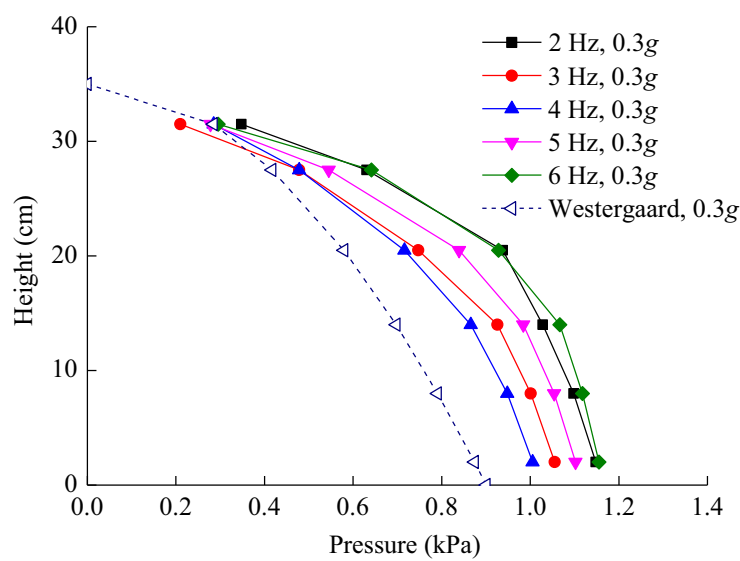

(c)

Fig. 12 Distribution of the maximum hydrodynamic pressures with different frequencies. a PGA $=0.1 g, \mathbf{b}$ PGA $=0.2 g, \mathbf{c}$ PGA $=0.3 g$ 
reflection, while the Westergaard's formula does not include the boundary effect. As a result, the water waves reflected at the side walls will enlarge the hydrodynamic pressures. Therefore, Westergaard's formula can accurately calculate the hydrodynamic pressure caused by sinusoidal wave in small lakes.

\subsection{Wolong wave action}

In the experiment, the hydrodynamic pressures caused by real seismic wave (Wolong wave) were analyzed. Figure 13 presents the hydrodynamic pressure recorded by the $\mathrm{P}_{1}$ sensor attached to the wall during the Wolong earthquake, together with the $0.2 g$ PGA. Compared with the sinusoidal waves, the pressure caused by Wolong wave displays similar changes, which is always in synchronization with the response of Wolong wave. For further analysis, the maximum hydrodynamic pressures generated at different heights are shown in Fig. 14. The hydrodynamic

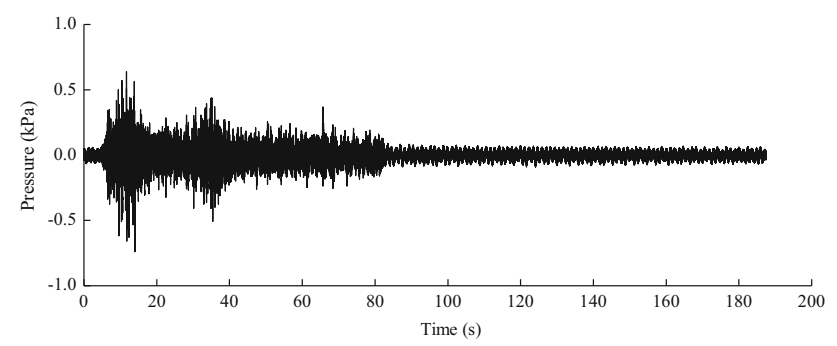

Fig. 13 Fluctuation of hydrodynamic pressure due to Wolong wave $(0.2 g)$

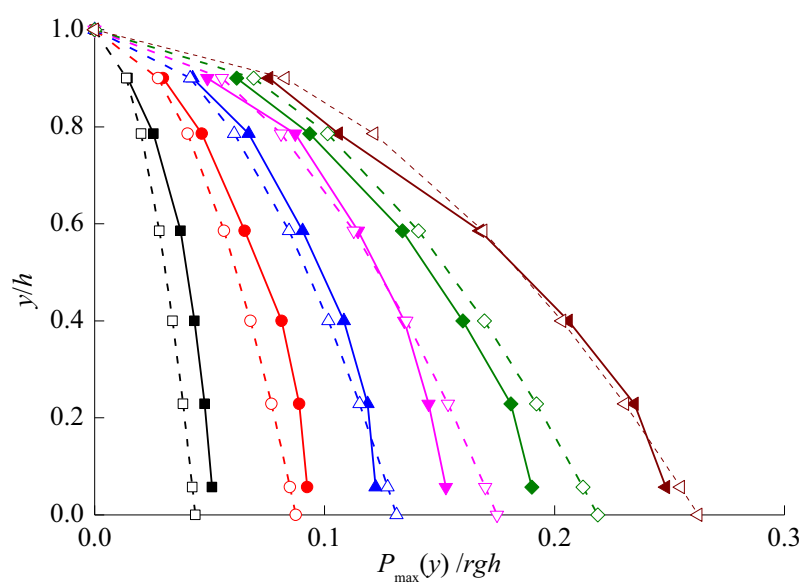

$\rightarrow 0.05 g$, Experimental $\rightarrow 0.10 g$, Experimental $\_0.15 g$, Experimental $\neg 0.20 \mathrm{~g}$, Experimental $\neg-0.25 \mathrm{~g}$, Experimental $\neg-0.30 \mathrm{~g}$, Experimental $-\square-0.05 g$, Westergaard - $-0.10 g$, Westergaard $-\triangle-0.15 g$, Westergaard $-\nabla-0.20 g$, Westergaard $-\diamond-0.25 g$, Westergaard $-\triangleleft-0.30 g$, Westergaard

Fig. 14 Comparison of the maximum hydrodynamic pressures pressures are normalized with the total hydrostatic pressure, and the sensor depths are normalized with reservoir depth. In Fig. 14, $y$ denotes the sensor heights, $P_{\max }(y)$ denotes the maximum hydrodynamic pressures at heights $y$, $h$ is the reservoir depth, $\rho$ is the unit density of water (1.0 t/ $\left.\mathrm{m}^{3}\right)$, and $g$ is the acceleration of gravity $\left(9.8 \mathrm{~m} / \mathrm{s}^{2}\right)$.

As observed in Fig. 14, the maximum hydrodynamic pressures along the water depth are increased from top to the bottom, and it is also found that the ratio of maximum hydrodynamic pressure to total hydrostatic pressure approximately grows from $5 \%$ to $25 \%$, increasing monotonously with seismic acceleration.

Comparison of the measured hydrodynamic pressures and Westergaard's formula is given in Fig. 14. It indicates that generally, the measured hydrodynamic pressures mostly match well with those calculated by the Westergaard's formula. As discussed earlier, there exists boundary effect, and hence, we can see that the experimental hydrodynamic pressures are higher than those induced in a semi-infinite reservoir. However, with the same maximum excitation acceleration, the input energy generated by the sinusoidal wave is greater than the seismic wave induced. Therefore, the hydrodynamic pressures induced by sinusoidal wave are greater than the values caused by seismic wave. As a result, the test data for hydrodynamic pressures caused by Wolong wave are mostly in good agreement with Westergaard's formula. Small deviation may be attributed to equipment error or human error in measurement.

The Westergaard's method is able to predict the earthquake-induced hydrodynamic pressure caused by Wolong wave in the small lake with reasonable accuracy. In the experiment, the most disadvantage condition of hydrodynamic pressure is considered, i.e., the side walls are vertical and rigid, and the hydrodynamic pressure at the side may be larger compared to the normal case. As reference to "Specifications for Seismic Design of Hydraulic Structure" (DL5073-2000), if an inclined upstream face is with a horizontal angle of $\theta$, the hydrodynamic pressure values should be multiplied by $\theta / 90$.

\section{Conclusions}

The characteristics of earthquake-induced hydrodynamic pressures were experimentally investigated using Wolong seismic wave and sinusoidal wave. Analysis of the fluctuation process of hydrodynamic pressure and the distribution of the maximum hydrodynamic pressure along the depth found that the water did not show resonance under action of Wolong wave $(2.35 \mathrm{~Hz})$ and sinusoidal waves $(2-6 \mathrm{~Hz})$. Conclusions are drawn as follows: 
1. When the input seismic excitation frequency is far from the fundamental frequency, the hydrodynamic pressure variation significantly followed the seismic acceleration wave motion. And the maximum hydrodynamic pressures were independent of the input seismic excitation frequencies, but have a positive correlation with PGAs.

2. The comparison of the theoretical values and experimental data shows that Westergaard's equation was slightly lower than the experimental values caused by sinusoidal waves, but in good agreement with the Wolong earthquake-induced hydrodynamic pressure in this small lake. It is indicated that Westergaard's formula to calculate hydrodynamic pressures caused by real seismic waves in the small lake is not a conservative approach.

3. In current risk analysis, the surge wave caused by earthquake or ice avalanches is the main potential threat to the glacier lake outburst, while the destructive earthquake-induced hydrodynamic pressures directly affect the stability of the moraine dam and are disastrous to human lives and properties along the shore.

Acknowledgements This work is financially supported by the Natural Science Foundation of China under contract No. 41571004; National Key Research and Development Program (Grant No. 2016YFC0802206); Research and Development Program of Science and Technology of China Railway Corporation (Grant No. 2015G002-N)

Open Access This article is distributed under the terms of the Creative Commons Attribution 4.0 International License (http:// creativecommons.org/licenses/by/4.0/), which permits unrestricted use, distribution, and reproduction in any medium, provided you give appropriate credit to the original author(s) and the source, provide a link to the Creative Commons license, and indicate if changes were made.

\section{References}

1. Cheng ZL, Zhu PY, Dang C et al (2008) Hazards of Debris Flow due to Glacier-Lake Outburst in Southeastern Tibet. J Glaciol Geocryol 30(6):954-959 (in Chinese)

2. Yang R, Zhu L, Wang Y et al (2012) Study on the variations of lake area and volume and their effect on the occurrence of outburst of MUDUI Glacier Lake in Southeastern Tibet. Prog Geogr 31(9):1133-1140 (in Chinese)

3. You Y, Cheng Z (2005) Modeling experiment of Debris Flow in Midui Gully, Tibet. J Mt Res 23(3):288-293

4. Yao LK, Qiu YL, Wei YX (2012) Challenges in construction of railway and highway from Sichuan to Tibet through Eastern Margin of Tibetan Plateau. J Southwest Jiaotong Univ 47(5):719-734 (in Chinese)

5. Du C, Yao LK, Huang YD et al (2016) Effects of seismic surge waves and implications for moraine-dammed lake outburst. Front Earth Sci 10(3):570-577

6. Cui P, Dang C, Scott ZCKM (2010) Debris flows resulting from Glacial-Lake outburst floods in Tibet, China. Phys Geogr 31(6):508-527

7. Zou DG, Zhou Y, Liang HI et al (2012) Dislocation of face-slabs of Zipingpu concrete face rockfill dam during Wenchuan earthquake. J Earthq Tsunami 06(2):261-279

8. Chakraborty D, Choudhury D (2014) Sliding stability of nonvertical waterfront retaining wall supporting inclined backfill subjected to pseudo-dynamic earthquake forces. Appl Ocean Res 47(2):174-182

9. Chakraborty D, Choudhury D (2014) Stability of non-vertical waterfront retaining wall supporting inclined backfill under earthquake and tsunami. Ocean Eng 78(1):1-10

10. Westergaard HM (1933) Water pressures on dams during earthquakes. Trans Am Soc Civ Eng 98(3):418-433

11. Zangar CN (1953) Hydrodynamic pressures on dams due to horizontal earthquakes. Proc Soc Exp Stress Anal 10:93-102

12. Chwang AT, Housner GW (1978) Hydrodynamic pressures on sloping dams during earthquakes. Part 1. Momentum method. J Fluid Mech 87(02):335-341

13. Chwang AT (1978) Hydrodynamic pressures on sloping dams during earthquakes. Part 2. Exact theory. J Fluid Mech 87(2):343-348

14. Wang MM, Chen JY, Xu Q et al (2013) Study on different height gravity hydrodynamic pressure and westergaard correction formula. Eng Mech 30(12):65-70 (in Chinese)

15. Saleh S, Madabhushi SPG (2011) Response of concrete dams on rigid and soil foundations under earthquake loading. J Earthq Tsunami 04(3):251-268

16. Liu N, Cheng ZL, Cui P et al (2013) Dammed Lake and risk management. Science Press, Marrickville

17. Clague JJ, Evans SG (2000) A review of catastrophic drainage of moraine-dammed lakes in British Columbia. Quatern Sci Rev 19(17-18):1763-1783

18. Cui P, Dang C, Zhuang JQ et al (2012) Landslide-dammed lake at Tangjiashan, Sichuan Province, China (triggered by the Wenchuan Earthquake, May 12, 2008): risk assessment, mitigation strategy, and lessons learned. Environ Earth Sci 65(4):1055-1065

19. Chen HY, Cui P, Chen XQ et al (2015) Laboratory experiments of water pressure loads acting on a downstream dam caused by ice avalanches. Landslides 12(6):1-8

20. Wang X, Liu SY, Guo WQ et al (2009) Hazard assessment of Moraine-dammed Lake outburst floods in the Himalayas, China. Acta Geogr Sin 64(7):782-790 